\title{
EL DEBATE ELECTORAL DEL 10-N DE 2019 EN ESPAÑA: LOS CANDIDATOS POLÍTICOS Y RTVE
}

\section{THE 10-N ELECTION DEBATE OF 2019 IN SPAIN: POLITICAL CANDIDATES AND RTVE}

Tania Brandariz Portela1. Universidad Complutense de Madrid. España. tabranda@ucm.es

\section{Cómo citar el artículo:}

Brandariz Portela, T. (2021). El debate electoral del 10-n de 2019 en españa: los candidatos políticos y RTVE. Revista de Ciencias de la Comunicación e Información, Vol. 26, 1-25. http://doi.org/10.35742/rcci.2021.26.e130

\section{RESUMEN}

Las campañas electorales tienen el objetivo de aumentar la participación para captar el voto del electorado. El encuentro privilegiado para acercarse a los ciudadanos es el debate, que en España supera los diez millones de espectadores. No obstante, los medios de comunicación convencionales son determinantes en las campañas. La televisión todavía es el medio escogido por los españoles, según el Centro de Investigaciones Sociológicas, para seguir información política en campaña electoral. El objetivo de esta investigación es analizar los discursos de los candidatos políticos en el debate electoral de las elecciones del 10 de noviembre de 2019 en España. Por otro lado, buscamos concluir si el discurso de la Radio y Televisión Española (RTVE) sobre el debate electoral en Twitter es una reproducción del discurso político o si se cumple la función de servicio público. Para el análisis del discurso político y de RTVE del debate electoral empleamos como metodología de análisis la teoría del framing. Las conclusiones de este estudio muestran que la televisión pública informó a la ciudadanía sin reproducir el discurso político, aunque los tuits dedicados al conflicto entre candidatos y la presentación de medidas del PSOE fueron los más frecuentes.

PALABRAS CLAVE: Debates electorales; Campañas; Encuadres; Agenda-setting; Candidatos; RTVE; Televisión; Twitter; Discursos.

\footnotetext{
1 Tania Brandariz Portela: Doctoranda en Periodismo en la Universidad Complutense de Madrid. Máster en Comunicación Política.
}

Recibido: 24/05/2021 - Aceptado: 15/04/2021 - Publicado: 05/05/2021 


\begin{abstract}
Electoral campaigns aim to increase participation to capture the votes of the electorate. In this sense, the privileged space to approach the citizens is the debate, which in Spain exceeds the million viewers. Although, the conventional media are decisive in campaigns. Television is still the main media outlet chosen by the Spanish citizens, according to the 'Center for Sociological Research', to follow political information of the electoral campaign. The objective of this research is to analyze the speeches of political candidates in the 10-N election debate in Spain. On the other hand, we seek to conclude whether the discourses of Spanish Radio and Television (RTVE) about the debate on Twitter are a reproduction of political discourse or whether the function of public service media is fulfilled. For the analysis of the political discourse and electoral debate in RTVE, we use framing theory as an analysis methodology. The findings of this study show that public television informed citizens without reproducing political discourse, although tweets dedicated to conflict between candidates and the presentation of PSOE measures were the most frequent.
\end{abstract}

KEYWORDS: Electoral debates; Campaigns; Framing; Agenda-setting; Candidates; RTVE; Television; Twitter; Discourses.

\title{
1. INTRODUCCIÓN
}

El nuevo entorno multipartidista en España obliga a los partidos nacionales a llegar a acuerdos para formar un Gobierno (Simón, 2017). La incapacidad de los candidatos a la presidencia para realizar pactos, y la investidura fallida después de las elecciones de abril de 2019, conduce a una repetición electoral que convoca a los ciudadanos a las urnas, de nuevo, el 10 de noviembre. Con la reforma de la Ley Electoral de 2016, que permite reducir el calendario electoral, los tiempos de la campaña se acortaron a la mitad, con ocho jornadas en las que las fuerzas políticas tuvieron la oportunidad de dirigirse al electorado para pedir el voto.

En este contexto las tecnologías digitales se integran cada vez más a la comunicación política (Lilleker et al., 2017). Los gabinetes de comunicación y las redes sociales, empleadas para ganar visibilidad y contar historias políticas (Kalsnes \& Olof, 2019) se han convertido en protagonistas, pero los medios de comunicación convencionales todavía continúan siendo determinantes para la esfera pública y para la deliberación sobre asuntos del sistema político (Boczkowski \& Mitchelstein, 2015). Recientemente se ha concluido que existe una equivalencia temática, una táctica política común y un discurso basado en la confrontación y la espectacularización tanto del lenguaje en televisión como en Twitter (Pérez y García, 2020). Un estudio de López y Oñate (2019) en Argentina, Perú, Ecuador, Honduras y Chile, concluye la coalición de agendas entre televisión es y candidatos, estableciéndose como pauta que las televisiones públicas se sitúen con los candidatos oficialistas y las privadas con la oposición (pp. 10-11).

Las campañas electorales tienen el objetivo de aumentar la participación de los ciudadanos para lograr su voto (Ohme, Marquart \& Fristensen 2019). En la campaña electoral de esta investigación se celebró un único debate televisado con los cinco 
candidatos a la presidencia del Gobierno: Pedro Sánchez, secretario general del PSOE; Pablo Casado, del Partido Popular (PP); Pablo Iglesias, de Unidas Podemos; Albert Rivera, de Ciudadanos y Santiago Abascal, de Vox. El encuentro fue organizado por las Academia de las Artes y de las Ciencias de la Televisión, en colaboración con Radio Televisión Española, Atresmedia y la FORTA. Estuvo dirigido por los periodistas Vicente Vallés y Ana Blanco.

\section{OBJETIVOS}

Las estrategias propuestas en las campañas tienen el objetivo de llegar al electorado, especialmente a los votantes afines e indecisos. Por lo tanto, las estrategias de comunicación de los candidatos políticos se convierten en relatos que se manifiestan a través de los marcos o frames que determinan la interpretación de un problema social. Los partidos políticos y los medios de comunicación tienen un peso determinante en la construcción de los discursos. En esta investigación, analizamos los discursos en el debate electoral, que todavía congrega audiencias en torno a doce millones de espectadores (Vidal, 2017) y que, como se desarrolla en el marco teórico propuesto, tiene una función pedagógica que, además, produce efectos en los votantes indecisos (Canel, 1998). Por otra parte, RTVE debe cumplir, en la cobertura del encuentro en Twitter, su función de servicio público. La intención de este análisis es comprobar si los discursos articulados en el debate por parte de los candidatos políticos se ven representados en el discurso en las redes sociales de @RTVE, cumpliendo la misión de orientar a la ciudadanía, o si la radiotelevisión pública ha elaborado un relato político propio.

\section{MARCO TEÓRICO}

\subsection{Los medios de comunicación y el sistema político}

El siglo XX fue partícipe del desarrollo de las teorías de efectos de los medios de comunicación. McCombs y Shaw (1972) ponen de manifiesto, en su análisis de los medios en campaña electoral, que el público percibe la relevancia que dan los medios a los temas, puesto que los emplean para organizar su propia agenda. De esta forma, la agenda de los medios es, en gran medida, la agenda pública (McCombs, 2006: 25). Años más tarde, la teoría del framing explicaría que no solo importan los temas sobre los que la gente habla, sino la forma en que lo hacen (Entman, 1993).

En el sistema de pluralismo polarizado (Hallin \& Mancini, 2004) de los países mediterráneos, como España, los medios de comunicación guardan estrechas relaciones con el sistema político. Los medios de comunicación son actores políticos "con intereses y metas genuinos que interactúan con otros, en un proceso de conflictividad y negociación permanente que involucra la generación de sentidos públicos" (Aruguete, 2017, p. 38). Por este motivo, los medios deben salvaguardar la figura de gatekeeper, prestando especial atención a los eventos de interés periodísticos, pues es en ellos donde adquiere importancia el sesgo partidista en la selección de mensajes (Haselmayer, Wagner \& Meyer, 2017).

Los medios de comunicación tienen la función de orientación del público. Para esto, los periodistas deben simplificar la complejidad de las noticias sobre el proceso 
electoral: lo sustancial reside en el enfoque o la línea bajo la que se presentan las noticias (Castromil y Rodríguez, 2010). En un intento por atraer audiencias, se ha instalado una tendencia a focalizar su atención en los candidatos políticos más que en sus acciones (Aruguete, 2013) lo que tiene un trasfondo ideológico: ignorar cuestiones estructurales (Edelman \& Piatigorsky, 1991).

\subsection{Agenda pública, medios y Framing}

En la mayor parte de los casos, existe un ajuste entre la agenda de los medios y la pública porque, en general, los medios tienen un buen sentido de lo que es importante para el público (Trigueros y Lacasa, 2018). Según el Barómetro Preelectoral del CIS (Centro de Investigaciones Sociológicas) de octubre de 2019, los temas que más preocupaban a los españoles, como primer problema, son el paro $(19,9 \%)$, los problemas de índole económica $(13,4 \%)$, las pensiones $(9,9 \%)$, problemas relacionados con la calidad del empleo $(6,4 \%)$, los relacionados con el Estado de Bienestar, que son educación y sanidad; y también la falta de acuerdos, lo que conduce a la inestabilidad política en España (2,6\%).

En los medios de comunicación surge una segunda campaña (Padilla, 2015). El debate electoral tiene dos objetivos: la confrontación intelectual y la lucha por imponerse al adversario (p. 107) y se han encontrado evidencias de que los debates electorales contribuyen al aprendizaje (Van Der Meer, Walter \& Aelst 2016). Aparte, se genera una interrelación entre el poder político, los medios de comunicación y la ciudadanía. Los actores políticos compiten por la atención de los medios. Por otro lado, los medios compiten entre ellos por atraer la atención de las audiencias (Donsbach, 1995). El debate también surge en la conversación en redes sociales. Además, se ha concluido que el mayor volumen de tuits viene dado siempre por una retransmisión televisiva (Deltell, 2014, p. 34).

Los debates televisados congregan audiencias de doce millones de espectadores (Vidal, 2017, p. 23). Constituyen el acontecimiento mediático más importante de una campaña electoral (Rúas y Quintas, 2020) siendo en ocasiones el más visto del año televisivo (Luengo, 2011). Existe cierto consenso entre los académicos en torno al hecho de que los debates tienen un impacto limitado en las preferencias electorales y que influyen actuando como refuerzo (López, Rivera y Araújo, 2017) sobre todo en los indecisos (Anstead, 2016). Por otro lado, se ha detectado que estos encuentros contribuyen al establecimiento de la agenda (Schrott, 1990). En los debates electorales convergen la agenda mediática, la política y la agenda pública (López, Rivera y Araújo, 2017). En la relación entre los periodistas y los políticos en los debates políticos televisados se dan negociaciones previas. Puede haber sillones, decidir si estar de pie detrás de los atriles e incluso plantearse preguntas realizadas por ciudadanos anónimos o la formulación de preguntas abiertas o cerradas (Barrientos, Caldevilla y Vargas, 2019, p. 20).

En el debate que se analiza, la participación de los moderadores se reduce a mínimos: controlar que las normas impuestas por los candidatos se cumplan. No obstante, redes sociales como Twitter se configuran como un espacio de definición de la agenda por parte de la televisión pública. Del mismo modo, las jornadas que superan la media diaria de tuits se correspondan con días en los que los partidos registran más cantidad 
de apariciones en medios convencionales, especialmente la televisión (Marcos, Alonso y López, 2021). Los debates electorales no son un vehículo directo entre los candidatos y los votantes: existe una mediación por parte de los medios de comunicación. El hecho de destacar a unos actores sobre otros, o mencionar un problema social en detrimento de otro, puede moldear la agenda (Richardson, Huddy \& Morgan., 2008).

\section{METODOLOGÍA}

Esta investigación se realiza con una metodología de análisis de contenido cualitativo (Jivkova, Padilla y Pernía, 2015) desde la teoría del framing (Bartolomé y Rodríguez, 2012; Entman, 2003). Con este objetivo, se procede a ver el debate de RTVE transcribiendo el discurso político del formato. Por otro lado, se asumen los bloques y los temas introducidos por los moderadores Ana Blanco y Vicente Vallés, que son: cohesión de España, política económica, política social, calidad democrática y política internacional. No obstante, los candidatos a la presidencia del Gobierno introducen sus propias medidas, ataques y propuestas (Benoit, 2003). La duración de las intervenciones de los candidatos es de cinco minutos por bloque; la apertura de cada uno de ellos y el minuto de oro, pactado por sorteo.

Para el análisis del debate electoral de la campaña de las elecciones del 10 de noviembre, asumimos las palabras clave del discurso a través de las temáticas introducidas por los candidatos; por otro lado, aplicamos la perspectiva del encuadre en base a las funciones de Entman (1993, p. 52) que son: definición del problema, atribución de responsabilidad, evaluación moral y tratamiento o recomendación. En lo que refiere al análisis de Twitter, hacemos una búsqueda avanzada en la red tomando los días 4 y 5 de noviembre de 2019; el del debate electoral y el posterior, filtrando con la cuenta @RTVE. Realizamos el análisis de los tuits atendiendo a la definición de Ardèvol-Abreu (2015) que distingue cinco tipos de marcos: de conflicto, de consecuencias, de interés humano, de moralidad y de atribución de responsabilidad. Con el análisis, podremos determinar los problemas sociales que se destacan desde RTVE; el bloque al que pertenecen dentro del debate, así como los candidatos políticos que gozan de mayor popularidad en el tratamiento mediático de la radio y televisión pública en su red social Twitter.

\section{DISCUSIÓN}

\subsection{Cohesión territorial}

La cuestión de la cohesión territorial, con la crisis de Cataluña, fue central en el debate. En la tabla 1 se incluyen los temas, con sus marcos, introducidos por cada candidato político. Posteriormente, aportamos las palabras clave utilizadas para interpretar el problema social. 
Tabla 1. Temáticas de los candidatos a la Presidencia del Gobierno en el bloque de cohesión territorial

\begin{tabular}{|c|c|}
\hline & Temáticas \\
\hline Pedro Sánchez & Crisis en Cataluña \\
\hline Pablo Casado & Desorden público en Cataluña \\
\hline Albert Rivera & Amenaza a la Democracia en Cataluña \\
\hline Santiago Abascal & Golpe de Estado permanente / autonomías \\
\hline Pablo Iglesias & $\begin{array}{c}\text { Mundo rural y servicios públicos / crisis en } \\
\text { Cataluña }\end{array}$ \\
\hline
\end{tabular}

Fuente: Debate electoral RTVE. Elaboración propia.

A excepción de Pablo Iglesias, que incorporó las dificultades de las personas del mundo rural por el acceso a los servicios públicos, evadiendo la crisis catalana; y de Santiago Abascal, que enfocó las autonomías en clave económica, insistiendo en que suponen un "despilfarro" y que obligan a escoger entre la dicotomía autonomías o pensiones, Pedro Sánchez, Pablo Casado y Albert Rivera enmarcaron la crisis en Cataluña.

Tabla 2. Palabras clave del discurso en el bloque de cohesión territorial

\begin{tabular}{|c|c|}
\hline Bloque 1. Cohesión de España & Palabras clave \\
\hline Pedro Sánchez & $\begin{array}{l}\text { Convivencia, independencia, confrontación, } \\
\text { encuentro, Declaración Unilateral de } \\
\text { Independencia, unidad, proporcionalidad, } \\
\text { firmeza democrática, derecha }\end{array}$ \\
\hline Pablo Casado & $\begin{array}{l}\text { Orden público, Constitución, libertad, } \\
\text { independentistas, nación española, seguridad } \\
\text { nacional, conciencia, concordia, Ley }\end{array}$ \\
\hline Albert Rivera & $\begin{array}{c}\text { Desorden público, amenaza, Democracia, } \\
\text { Estado de derecho, libertad, bestias taradas, } \\
\text { compatriota, Constitución, convivencia, } \\
\text { respeto, Ley, } 155\end{array}$ \\
\hline Santiago Abascal & $\begin{array}{l}\text { Separatismo, Golpe de Estado permanente, } \\
\text { libertad, nación, } 155 \text {, criminales, Estado de } \\
\text { las autonomías, políticas totalitarias }\end{array}$ \\
\hline Pablo Iglesias & $\begin{array}{l}\text { Rural, servicios públicos, patria, diálogo, } \\
\text { reconciliación, nación de naciones }\end{array}$ \\
\hline
\end{tabular}

Fuente: Debate electoral RTVE. Elaboración propia. 
Desde una posición presidencialista, Pedro Sánchez arrojó el marco de análisis de la definición del problema (crisis en Cataluña) desde su interpretación: "La crisis que se vive en Cataluña es de convivencia, no de independencia". La justificación de esta cuestión la encontró en su crítica a Casado, a quien insistió que la Declaración Unilateral de Independencia (DUI) no suponía un problema de independencia. Evitando el concepto de diálogo, la solución que propuso fue "aumentar los espacios de encuentro y reducir los de confrontación". Su tratamiento o recomendación del problema se centró en la concordia desde la educación, modificación de la Ley General Audiovisual e incorporación en el Código Penal de la prohibición de referéndums ilegales. Otra cuestión que repitió a lo largo del debate fue la de los tres principios del PSOE en torno a esta cuestión: legalidad democrática, proporcionalidad y unidad. Con la intención de marcar posición con respecto a Pablo Iglesias en torno a la cuestión catalana, especificó Pedro Sánchez su desacuerdo con el candidato de la formación morada a través de un juego de palabras: mientras Pablo Iglesias habló de presos políticos, el PSOE de políticos presos "por haber quebrado la legalidad democrática". Por otro lado, en su crítica a lo que denomina como "la derecha" -PP, Ciudadanos y Vox-, lo representó con un matiz: "En la derecha tienen un problema con Cataluña; nosotros tendremos un problema en, pero ellos con".

Uno de los focos de tensión de este bloque se produjo con la insistente pregunta del líder popular Pablo Casado Casado al socialista Pedro Sánchez: "¿Qué es para usted la nación española?". Insistía Casado a Sánchez: "Una persona que no cree en la nación española no merece presentarse a presidirla". El candidato popular realizó una crítica explícita y abierta hacia Sánchez a lo largo de todo el debate. Según apuntó, "para el señor Sánchez Cataluña sí es una nación y España es una nación de naciones". La solución para el Partido Popular sería "garantizar el orden en las calles, la libertad, conciencia y concordia", aplicando la Constitución. El candidato del Partido Popular, Pablo Casado, articuló su discurso en torno a la interpretación de la crisis catalana. A juicio del PP, la atribución de responsabilidad recae sobre Sánchez, a quien se hace responsable de que no se celebren elecciones "en libertad en Cataluña", por no haber "aplicado la ley de seguridad nacional" o el "requerimiento para que Torra cumpla la Constitución".

Albert Rivera comenzó el debate con un adoquín, a través del que introdujo la cuestión de la crisis catalana. La denominó como un problema de orden público y una amenaza al Estado de derecho. La solución del problema, según el candidato, consistiría en aplicar la Constitución para cesar a Quim Torra, presidente de la Generalitat de Cataluña. En la interpretación de Ciudadanos, lo que pretenden los "separatistas" es construir "fronteras entre compatriotas", cuando lo que hace falta es "convivencia y grandes dosis de respeto, pero también a la Ley". Resulta interesante como la ley sirve de concepto para articular la democracia: fuera de ella "es la selva", mientras que dentro de ella está "la Constitución". La línea de ataque de Ciudadanos son los "40 años de cesiones del bipartidismo", que contrapone con la necesidad de aplicar la Constitución (155) "con serenidad" para proteger a los españoles "que nunca protestan, pero que están olvidados".

En el discurso de Vox, Santiago Abascal basó su mensaje en dos ejes: el ataque a los cuatro oponentes, por un lado; y la proposición de medidas, por otro. En este sentido, Abascal acusó a Zapatero de eliminar del Código Penal la penalización de los 
referéndums. Por otro, a Rajoy, de no recuperar la penalización. En el presente, acusa a Sánchez de aparecer al lado "de una bandera española" para defender después la plurinacionalidad. En el discurso de Vox, la cuestión catalana se resume en una premisa: "Golpe de Estado permanente" por haber premiado "a la traición de la nación". A juicio de Abascal, esto ha producido una destrucción de "la libertad en Cataluña", que solo se puede recuperar con la "suspensión de las autonomías" y la "ilegalización de los partidos nacionalistas". La justificación para estas medidas sería: "el estado de las autonomías ha fracasado" porque ha premiado a las "regiones gobernadas por los más traidores y desleales", con "políticas totalitarias que nos han hecho desiguales".

Por otro lado, desde Unidas Podemos, con un discurso que se alejó de la crisis catalana, se aportó un cambio de marco. Dijo Pablo Iglesias que hablar de cohesión territorial centrándose solo en Cataluña es una "falta de respeto" a los españoles, porque el mundo rural conoce otro problema territorial: no tener acceso a los servicios públicos. También se posicionó, aunque de manera secundaria, realizando una crítica a los candidatos por intentar arrojar "la medida más dura" en Cataluña cuando, a su juicio, la crisis catalana "solo se puede resolver con diálogo, sentido común y mano izquierda". La justificación del candidato de la formación morada parte de la premisa de que España "no es centralista, se hablan muchas lenguas, identidades nacionales", por lo que, si hay "conflictos que solucionar", solo podrá ser a través del diálogo.

\subsection{Política económica}

El bloque de política económica fue introducido, por parte de los moderadores, bajo la premisa de la ralentización de la economía y el temor a una nueva crisis en España. Ante esta realidad, el Partido Popular, Ciudadanos y Vox apuestan por discursos centrados en bajadas de impuestos; PSOE y Unidas Podemos, por el aumento del gasto. Así, procedemos al análisis de la comunicación política de las fuerzas políticas en esta materia.

Tabla 3. Temáticas de los candidatos a la Presidencia del Gobierno en el bloque de política económica

\begin{tabular}{|c|c|}
\hline Pablo Iglesias & Temáticas \\
\hline Pablo Casado & $\begin{array}{c}\text { Desaceleración que se puede convertir en } \\
\text { crisis. Protección del Estado de Bienestar }\end{array}$ \\
\hline Albert Rivera & $\begin{array}{c}\text { Crisis que trae el socialismo / Crear empleo } \\
\text { La crisis imposibilita crear una familia / } \\
\text { Corrupción del bipartidismo }\end{array}$ \\
\hline Santiago Abascal & Despilfarro de las autonomías vs pensiones \\
\hline Pedro Sánchez & Enfriamiento de la economía: transición justa \\
\hline
\end{tabular}

Fuente: Debate electoral RTVE. Elaboración propia. 


\section{EL DEBATE ELECTORAL DEL 10-N DE 2019 EN ESPAÑA: LOS CANDIDATOS POLÍTICOS Y RTVE}

En la tabla 3 se recogen las temáticas de los candidatos en la cuestión de la economía, con sus respectivas interpretaciones. Destaca la aportación de Albert Rivera que, además de incorporar la idea de la revolución en las familias, hizo hincapié también en la corrupción del bipartidismo, en su relación con el lastre que supone para la economía.

Tabla 4. Palabras clave del discurso en el bloque de política económica

\begin{tabular}{|c|c|}
\hline Bloque 2. Política económica & Palabras clave \\
\hline Pedro Sánchez & $\begin{array}{c}\text { Enfriamiento de la economía, Salario Mínimo } \\
\text { Interprofesional, emergencia climática, empleo }\end{array}$ \\
\hline Pablo Casado & Crisis, rescate, socialismo, empleo \\
\hline Albert Rivera & $\begin{array}{c}\text { Familia, natalidad, conciliación, corrupción, } \\
\text { 'Impuesto corrupción bipartidismo', Gobierno } \\
\text { transparente, emprendedores }\end{array}$ \\
\hline Santiago Abascal & $\begin{array}{c}\text { Políticas de gasto, clases medias y } \\
\text { trabajadoras, autonomías, pensiones, natalidad }\end{array}$ \\
\hline Pablo Iglesias & $\begin{array}{c}\text { Desaceleración, crisis, recortes, Constitución, } \\
\text { Índice de Precios al Consumidor, fraude fiscal, } \\
\text { Estado de Bienestar, temporalidad }\end{array}$ \\
\hline
\end{tabular}

Fuente: Debate electoral RTVE. Elaboración propia.

El bloque de política económica, que comenzó Pablo Iglesias, se articuló sobre la interpretación de la desaceleración o crisis: se tienen que hacer recortes "por abajo o por arriba". En cuanto al tratamiento del problema de la crisis, Iglesias emplea la Constitución como programa político para hacerle frente. En su definición de la Constitución, más allá de su uso para defender la soberanía o aplicar el Artículo 155, "no puede ser un adoquín para arrojar al adversario sino una caja de herramientas para proteger a la gente". En su discurso, anunció una ristra de artículos haciendo hincapié en el 128: "Toda la riqueza del país estará subordinada al país general". En cuanto a las medidas para hacer frente, introdujo la cuestión del "fraude fiscal" propiciado por las "empresas del IBEX". En este bloque Iglesias destacó, de nuevo, la necesidad de gobernar con el PSOE. Apuntaba a Sánchez, de manera reiterada, que "si no hay Gobierno de izquierdas, habrá de derechas". Relacionando los futuros acuerdos de Gobierno con la economía, le proponía a Sánchez "gobernar juntos" y publicar las listas de "amnistiados fiscales".

El candidato popular, Pablo Casado, optó por un discurso basado en dos ejes, que supusieron su definición del problema económico en España: el socialismo trae la crisis económica (años 90 y época de Zapatero, a la que denomina "el mayor hachazo") y la necesidad de la creación de empleo. Se remitió al año 2011, "con 3 millones de parados y pensiones congeladas" y a la actualidad, con un Sánchez que "niega la realidad". 
El líder de Ciudadanos, Albert Rivera, centró su mensaje en la familia o, en términos metafóricos, lo que denominó como necesidad de una "revolución en las familias". La definición del problema para Ciudadanos es que "se ha perdido la natalidad". En su crítica al PSOE insistió, del mismo modo que Casado y Abascal, en que Sánchez subiría los impuestos. Su interpretación de este hecho es que "una economía que estrangula a quien genera riqueza" es "un país que no tiene dignidad". La estrategia de Ciudadanos se basó en relacionar la economía con lo que denominaron ICB (Impuesto de Corrupción al Bipartidismo). En la línea de elecciones pasadas, la estrategia consistió en una acusación al PSOE y al PP y en la necesidad de un "Gobierno transparente". De acuerdo con Abascal, apuntó también que el Estado Autonómico, en ocasiones, había sido "un cachondeo".

El candidato de Vox, Santiago Abascal, en su definición del problema económico en España, apuntó a "un marco estructural que nos arruina" y basado en dos políticas de gasto: estado de las autonomías y la emigración ilegal. Según entiende, el "despilfarro de las autonomías" obliga a escoger entre estas "que arruinan y dividen" o las pensiones. La estrategia de Vox se podría resumir en la siguiente afirmación de Abascal, reflejada en una intervención en el debate: "Para los españoles más humildes España es su único patrimonio, y solo los ricos pueden permitirse el lujo de no tener patria".

Pedro Sánchez, en contraposición al resto de candidatos y por su posición de Presidente, obvió la palabra crisis, aludiendo al término enfriamiento de la economía. La estrategia consistió, por un lado, en criticar a los Gobiernos del Partido Popular, con la bajada de impuestos y los pensionistas que habían perdido poder adquisitivo. Por otra parte, enfatizó las buenas actuaciones del PSOE "en 18 meses", así como la necesidad de una "mirada al futuro" a partir de los "pilares" del partido: crecer por encima de la media europea o subir el SMI, entre otros. Además, anunció la vicepresidencia económica en caso de presidir el Gobierno, una estrategia que empleó en más de una ocasión a lo largo del debate. De nuevo, marcó posición con respecto a Iglesias a través de la percepción que el PSOE tiene sobre la figura del empresario. Desde el PSOE, el marco de interpretación es que si los empresarios "pagan impuestos y generan riqueza", no existe problema "si donan recursos".

\subsection{Política social e igualdad}

En cuanto al bloque de Política social e igualdad, el debate se produjo en torno a la educación, sanidad, pensiones y las políticas feministas. En el caso de Albert Rivera, se hizo hincapié en lo que denominó como revolución de la igualdad, según la cual todos los ciudadanos, en España, deben tener los mismos "derechos" independientemente de su lugar de origen, haciendo referencia a las autonomías. Pablo Casado dedicó un espacio generoso a culpar al PSOE de la destrucción del empleo; Iglesias reservó casi todo su tiempo para la cuestión de las políticas sociales y de las políticas feministas. Pedro Sánchez englobó las políticas sociales y el feminismo en el mismo marco de discurso, y elaboró una crítica a la derecha cobarde y la ultraderecha agresiva. Santiago Abascal aprovechó el bloque para hablar de dos cuestiones: emergencias sociales y necesidad de fronteras para mantener la seguridad. 


\section{EL DEBATE ELECTORAL DEL 10-N DE 2019 EN ESPAÑA: LOS CANDIDATOS POLÍTICOS Y RTVE}

Tabla 5. Temáticas de los candidatos a la Presidencia del Gobierno en el bloque de política social e igualdad

\begin{tabular}{|c|c|}
\hline Albert Rivera & Temáticas \\
\hline Pablo Casado & $\begin{array}{c}\text { Ciclo vital: formarse, tener un trabajo digno y una } \\
\text { pensión / Revolución de la igualdad - Nación de } \\
\text { ciudadanos libres e iguales }\end{array}$ \\
\hline Pablo Iglesias & $\begin{array}{c}\text { PSOE destruye empleo y no se sostienen las } \\
\text { pensiones / Logros del Partido Popular }\end{array}$ \\
\hline Pedro Sánchez & $\begin{array}{c}\text { Violencia machista y políticas feministas / Políticas } \\
\text { sociales }\end{array}$ \\
\hline Santiago Abascal & $\begin{array}{c}\text { Feminismo y políticas sociales / Ataque a la } \\
\text { derecha y la ultraderecha }\end{array}$ \\
\hline & Emergencias sociales / Seguridad - fronteras \\
\hline
\end{tabular}

Fuente: Debate electoral RTVE. Elaboración propia.

El bloque de política social e igualdad fue introducido por la periodista Ana Blanco, que apuntó la ausencia de mujeres como candidatas a la presidencia del Gobierno. "Hablarán de paridad, pero no es una foto de igualdad", dijo. La introducción del bloque no logró que los candidatos reservasen parte de su discurso a la igualdad entre hombres y mujeres, que tuvo poca presencia en este espacio privilegiado de campaña electoral.

Tabla 6. Palabras clave del discurso en el bloque de política social e igualdad

\begin{tabular}{|c|c|}
\hline Bloque 3. Política social e igualdad & Palabras clave \\
\hline Pedro Sánchez & $\begin{array}{c}\text { Gobierno, paridad, derecha cobarde, ultraderecha } \\
\text { agresiva, público, Estado de Bienestar, }\end{array}$ \\
\hline Pablo Casado & Empleo, pensiones \\
\hline Albert Rivera & $\begin{array}{c}\text { Familia, paro, contratos basura, autónomos, } \\
\text { nación, libertad, revolución de igualdad }\end{array}$ \\
\hline Santiago Abascal & $\begin{array}{c}\text { España, emergencia social, odios viejos, } \\
\text { enemigos de España, seguridad, efecto llamada, } \\
\text { fronteras }\end{array}$ \\
\hline Pablo Iglesias & $\begin{array}{c}\text { Políticas feministas, servicios públicos, educación, } \\
\text { sanidad, Constitución }\end{array}$ \\
\hline
\end{tabular}

Fuente: Debate electoral de RTVE. Elaboración propia.

En este bloque, iniciado por Albert Rivera, la estrategia de Ciudadanos partió de la premisa de un país que se preocupe por las familias. El principal problema de este país, bajo la interpretación de Ciudadanos y atendiendo al plano económico, es el 
paro. La proposición ante este problema es un contrato indefinido y proteger a los autónomos. En el ámbito social, desde Ciudadanos, se apunta que España es una "nación de ciudadanos libres e iguales" independientemente del lugar en el que vivan pero, en España, "una de las desigualdades más grandes que hay es vivir en un pueblo o en una capital". En la atribución de responsabilidad, se culpa a los nacionalistas de que exista desigualdad de condiciones en el acceso al funcionariado y que traben "la verdadera revolución de la igualdad".

El discurso del Partido Popular, en este bloque de política social e igualdad, consistió de nuevo en un recordatorio de medidas del pasado, bien hechas por parte del PP y mal hechas por parte del PSOE. Los temas sobre los que se articuló la estrategia de ataque fueron: empleo, sanidad y educación. Casado atacó a Sánchez por provocar que "cayese la contratación indefinida". También porque cuando llegó el PP en 2011, se encontró con deuda sanitaria. La proposición del PP en política social pasaría por: incremento de becas, MIR educativo a nivel nacional, español como lengua vehicular y bilingüismo en la escuela pública y privada.

Por su parte, Pablo Iglesias introdujo el bloque, en respuesta a Ana Blanco, diciendo que "en las crisis, son las mujeres las que más sufren", insistiendo en que las políticas sociales en España deben ser feministas. Propuso medidas como educación de 0 a 3 años gratuita o la modificación del Código Penal para que solo "sí sea sí", en referencia a que todo delito contra la libertad sexual sea considerado como una violación. Desde Podemos, Pablo Iglesias criticó que, también en este bloque, se mencionase a Cataluña, insistiendo en la educación y los servicios públicos. Además, empleó la Constitución, de nuevo, para defender los derechos sociales y no solo la unidad en Cataluña: "La educación y la sanidad son un derecho, lo dice la Constitución". Asimismo, Iglesias mencionó la cuestión del mercado del alquiler y la limitación de sus precio, así como lo que denomina como los "olvidados": Kelly's, militares de más de 45 años, el derecho al bienestar animal o mantener la banca pública.

El candidato socialista, Pedro Sánchez, en su estrategia en torno a las políticas de igualdad, introdujo el debate a través del feminismo, mencionando a Ana Blanco que "había que mejorar en paridad", pero que el Parlamento de España tenía el mayor número de mujeres y el consejo de ministras con más mujeres del mundo. Culpó al Partido Popular de "dejar una sociedad con menos derechos", haciendo referencia a la cuestión de la pobreza infantil. Como solución planteó medidas de cara al futuro como, por ejemplo, la gratuidad de 0 a 3 años o multiplicar las becas y derogar la 'Ley Mordaza'. En su línea de ataque, Pedro Sánchez increpó a la ultraderecha y socios a los que denomina, a lo largo del debate, como la derecha cobarde y la ultraderecha agresiva, por querer acabar con las Comunidades Autónomas (CCAA) derogar la Ley de violencia de género, eliminar partidos nacionalistas democráticos, privatizar el sistema público de pensiones o ilegalizar el aborto, entre otras cuestiones.

Desde Vox, Santiago Abascal plantea el discurso en clave dicotómica: los viejos odios -como desenterrar al dictador Francisco Franco, representados por el PSOE- y las emergencias sociales, que serían, según apunta: un $32 \%$ de paro juvenil o "pensiones de miseria", entre otras cuestiones. En esta línea, Abascal articuló el concepto de seguridad "para las mujeres y para los españoles" en contraposición con la Ley contra la violencia de género. Según entiende, esta "convierte a los hombres presuntamente 
en culpables". Aparte, la relaciona con las "denuncias falsas" y propone como solución la cadena perpetua. Para justificar la eliminación de las autonomías, se refiere al concepto igualdad de todos los españoles.

\subsection{Calidad democrática}

En el bloque de calidad democrática, Pablo Casado optó por una crítica al PSOE por "no regenerar" lo que habían prometido en la moción de censura; por su parte, Iglesias insistió en la necesidad de Sánchez de dejar claro con quién se pretendía pactar, realizando una fuerte crítica a Santiago Abascal por comparar, en la Guerra Civil, al bando republicano con el nacional. Pedro Sánchez insistió en un Gobierno en solitario y en los derechos logrados por el PSOE, frente a la ausencia de libertades del pasado. Por su parte, Rivera dejó entrever su posición en lo relativo de la memoria histórica, a la que no considera tan importante como "el presente y el futuro". El presidente de Vox, Santiago Abascal, aprovechó su espacio para hablar, de nuevo, de las emergencias sociales pero sobre todo, para arrojar su interpretación sobre la exhumación del dictador Francisco Franco: la memoria histórica solo sirve "para confrontar" y Vox representa lo que los "españoles necesitaban": el derecho a disentir.

Tabla 7. Temáticas de los candidatos a la Presidencia del Gobierno en el bloque de calidad democrática

\begin{tabular}{|c|c|}
\hline Pablo Casado & Temáticas \\
\hline Pablo Iglesias & $\begin{array}{c}\text { Crítica al PSOE por no regenerar tras la moción } \\
\text { de censura }\end{array}$ \\
\hline Pedro Sánchez & $\begin{array}{c}\text { Necesidad de que se clarifiquen pactos / Crítica a } \\
\text { Santiago Abascal por cuestión de la memoria } \\
\text { histórica }\end{array}$ \\
\hline Albert Rivera & $\begin{array}{c}\text { Gobierno de la lista más votada e insistencia en } \\
\text { que no existen pactos / Derechos vs represión } \\
\text { Ley electoral / Memoria histórica es menos } \\
\text { importante que mirar al presente y al futuro }\end{array}$ \\
\hline Santiago Abascal & $\begin{array}{c}\text { Emergencias sociales / Seguridad - fronteras / } \\
\text { Memoria histórica es confrontar / Calidad } \\
\text { democrática es el derecho a disentir }\end{array}$ \\
\hline
\end{tabular}

Fuente: Debate electoral RTVE. Elaboración propia.

El discurso que abrió este bloque fue el de Pablo Casado que partió, en esta ocasión también, de un ataque a Pedro Sánchez en base a dos cuestiones: moción de censura e instrumentalización de la Justicia, acusando al secretario general del PSOE de conocer la sentencia de Francisco Franco o de los "sediciosos en Cataluña" antes de que se hiciese pública. Desde el Partido Popular, como se dejó claro a lo largo del debate: "El peligro para la calidad democrática es usted" y "Pactar con independentistas le inhabilita como Presidente del Gobierno". 
Pablo Iglesias basó su discurso en justificar que la "decencia" pasaba por decir con quién quería gobernar cada uno. Para ello explicó que España es un sistema parlamentario, no presidencialista, insistiendo en un Gobierno de coalición de izquierdas y apuntando que no se entendía que el PSOE llegase a un acuerdo con la derecha.

Tabla 8. Palabras clave del discurso en el bloque de calidad democrática

\begin{tabular}{|c|c|}
\hline Bloque 4. Calidad democrática & Palabras clave \\
\hline Pedro Sánchez & $\begin{array}{c}\text { Lista más votada, España democrática, libertad, } \\
\text { Europa, feminismo, tolerancia, corrupción PP, } \\
\text { ultraderecha }\end{array}$ \\
\hline Pablo Casado & $\begin{array}{c}\text { Pactos, independentistas, peligro democrático, } \\
\text { Sánchez }\end{array}$ \\
\hline Albert Rivera & $\begin{array}{l}\text { Regeneración democrática, Ley electoral, } \\
\text { separatistas, sentencia ERE, división, futuro }\end{array}$ \\
\hline Santiago Abascal & $\begin{array}{l}\text { Régimen totalitario, Constitución, viejos odios, } \\
\text { orden constitucional, derecho a disentir }\end{array}$ \\
\hline Pablo Iglesias & $\begin{array}{l}\text { Pactos, Gobierno de coalición, sistemas } \\
\text { públicos, Constitución, derechos sociales }\end{array}$ \\
\hline
\end{tabular}

Fuente: Debate electoral RTVE. Elaboración propia.

El momento tenso de este bloque lo protagonizaron Santiago Abascal y Pablo Iglesias, cuando el último contestó que ser víctima de ETA no implica ir dando lecciones de "víctima del terrorismo". Para argumentar esto, Iglesias apuntó que en Unidas Podemos tenían en sus filas a víctimas que "hacen su trabajo" para que España "sea un país mejor". De nuevo, Iglesias volvió a apelar a la Constitución, de la que decía que no es "un ladrillo para arrojar al adversario" sino un "programa político".

El candidato socialista, Pedro Sánchez, utilizó el bloque de calidad democrática para arrojar la premisa: "La España democrática es fruto del perdón pero no puede ser producto del olvido". En este sentido, introdujo los conceptos de democracia, Europa, feminismo y tolerancia. Aseguró, en una ocasión, que no se iba a dar una gran coalición con el Partido Popular.

Albert Rivera aprovechó el bloque de calidad democrática para introducir su propuesta: nueva Ley Electoral. Desde Ciudadanos se hizo hincapié en la cuestión de la corrupción; Albert Rivera preguntó a Sánchez si con la sentencia de los ERE, si resultaba condenatoria, esperaba dimitir. En lo relativo a la memoria histórica argumentó que estaba "harto de un país que se divide por gente como ustedes", y que había que "superar el pasado y mirar al futuro". 
El candidato de Vox, Santiago Abascal, articuló la estrategia de relacionar las leyes de memoria histórica con la confrontación, por entender que, tanto el bando republicano como el nacional, "se abrazaron en la Constitución". A juicio de Vox, el PSOE pretendía rescatar viejos odios. En su línea de ataque y por lo tanto, de atribución de responsabilidad, Vox también acusó a Podemos de defender un régimen totalitario. En este sentido, insistió en que la izquierda cuenta "con una superioridad moral" que había anulado el derecho a disentir, que es lo que representa "la calidad democrática".

\subsection{Política internacional}

El último bloque, dedicado a la política internacional, fue en el que los partidos políticos mostraron mayor discrepancia. Santiago Abascal dedicó un amplio espacio a hablar de la soberanía dentro de las naciones y de las fronteras que, a su juicio, había que levantar en España. Rivera reservó su espacio para defender la Unidad de España en Latinoamérica y en Europa. Sánchez, con un discurso más complejo, habló de un proyecto común europeo, a la vez que empleó a Europa para halagar el cordón sanitario que se le hizo a la extrema derecha. Pablo Casado, en su insistencia por articular una estrategia constante de ataque al PSOE y Sánchez, culpó a los socialistas de la emigración ilegal, a la vez que propuso una política agraria común. Y Pablo Iglesias dedicó prácticamente la totalidad del bloque a defender que, frente a la desaceleración económica, la solución era: "seguridad a los trabajadores frente al IBEX 35".

Tabla 9. Temáticas de los candidatos a la Presidencia del Gobierno en el bloque de política internacional

\begin{tabular}{|c|c|}
\hline & Temáticas \\
\hline Santiago Abascal & $\begin{array}{c}\text { Soberanía dentro de las fronteras / Europa - } \\
\text { Bruselas }\end{array}$ \\
\hline Albert Rivera & España en Europa y Latinoamérica \\
\hline Pedro Sánchez & $\begin{array}{l}\text { Política de migración humanitaria y proyecto común } \\
\text { europeo / Cordón sanitario en Europa }\end{array}$ \\
\hline Pablo Casado & $\begin{array}{c}\text { Política agraria común / Emigración ilegal por culpa } \\
\text { del socialismo }\end{array}$ \\
\hline Pablo Iglesias & $\begin{array}{l}\text { Desaceleración económica y Guerra comercial: } \\
\text { Seguridad a los trabajadores frente al IBEX } 35\end{array}$ \\
\hline
\end{tabular}

Fuente: Debate electoral RTVE. Elaboración propia.

Los periodistas Vicente Vallés y Ana Blanco introdujeron el bloque mediante la cuestión de la deportación de emigrantes y la construcción de un muro infranqueable propuesto por Vox. La estrategia introducida por Santiago Abascal, en un contexto de debate sobre Europa, fue la de afirmar, en su definición del problema, que "no hay nación sin fronteras", relacionando la política internacional con la soberanía de las 
naciones. Desde Vox entienden que la solución es dicotómica: la identidad (representada por Vox) o la disolución.

Tabla 10. Palabras clave del discurso en el bloque de política internacional

\begin{tabular}{|c|c|}
\hline Bloque 5. Política internacional & Palabras clave \\
\hline Pedro Sánchez & $\begin{array}{c}\text { Entradas irregulares, política de migración } \\
\text { humanitaria, Europa, cordón sanitario, Gobierno } \\
\text { progresista }\end{array}$ \\
\hline Pablo Casado & $\begin{array}{c}\text { Prisión permanente revisable, seguridad, política } \\
\text { europea }\end{array}$ \\
\hline Albert Rivera & $\begin{array}{c}\text { Hispanohablantes, cultural, español, } \\
\text { Latinoamérica, Europa, Democracia, libre } \\
\text { comercio }\end{array}$ \\
\hline Santiago Abascal & $\begin{array}{c}\text { Soberanía, fronteras, nación, emigración ilegal, } \\
\text { identidad, Europa-Bruselas, islamización, libre } \\
\text { comercio, España }\end{array}$ \\
\hline Pablo Iglesias & $\begin{array}{c}\text { Desaceleración económica, guerra comercial, } \\
\text { inseguridad, seguridad a la gente, soberanía, } \\
\text { medidas de Gobierno, impuestos, IBEX 35, } \\
\text { multinacionales, acuerdos de Gobierno }\end{array}$ \\
\hline
\end{tabular}

Fuente: Debate electoral RTVE. Elaboración propia.

Al hablar de Europa, Abascal plantea el concepto estableciendo una relación con Bruselas. Según apunta el partido de extrema derecha, el problema es que las élites de Bruselas "imponen la inmigración masiva" y la "islamización", lo que provoca crisis de convivencia. Por eso la solución, para el partido de Abascal, es la soberanía de las naciones aprovechando el "patrimonio", que es el idioma.

La estrategia de Albert Rivera consistió en explicar que España, en la actualidad, no tiene ningún protagonismo en los "problemas importantes". La solución al problema pasaría por poner en alza la cultura española. Desde Ciudadanos se entiende que este hecho se forjará en una Europa "unida" y en Latinoamérica, por ser ambas "el futuro". Por un lado, en lo relativo a Latinoamérica, colaborando con los países con gobiernos de "dictadores" para ayudarles en su transición a la democracia. En el caso de Europa, Rivera trajo de nuevo al debate la cuestión de la crisis en Cataluña, volviendo a insistir en la defensa de la Unidad de España, pero "en Europa". Además, desde Ciudadanos se vuelve a mencionar lo que consideran el vehículo, la economía, afirmando que "el comercio es la civilización". Para esto hay que apostar por "los productos propios" y los "acuerdos de libre comercio".

Pedro Sánchez recogió la cuestión de la migración para articular el bloque sobre política internacional, a la que definió como "hecho histórico" y no coyuntural que se restrinja a la llegada del PSOE, en el marco de que al otro lado hay "seres humanos". En este sentido, Sánchez aprovechó la temática de Europa para hablar también del cordón sanitario a la ultraderecha, afirmando que la justicia se cumple "dentro y fuera 
de las fronteras". La propuesta del PSOE pasa por un proyecto común europeo caracterizado por políticas sociales.

Pablo Casado articuló su discurso sobre el bloque de política internacional en torno a la necesidad de introducir más supuestos en la prisión permanente revisable, aludiendo a la necesidad de preservar la seguridad en las calles. En lo relativo a Europa, Casado argumentó la necesidad de una política europea "en la que España sea esencial". En la atribución de responsabilidad, de nuevo, se mencionó la cuestión de la emigración ilegal, acusando a Zapatero de la peor crisis de los cayucos y diciéndole a Sánchez que es un incompetente "absoluto" para la emigración.

Con el objetivo de dar un giro al concepto de seguridad que había introducido la derecha, Pablo Iglesias optó por darle otra significación: "ni muros, ni racismo". Desde Podemos se apostó por la "seguridad a la gente frente a las inseguridades de la desaceleración y la guerra comercial”, que ejemplificó con el caso de los taxistas y con las familias amenazadas por un fondo buitre, el "mayor casero de España". Así, dando un giro al concepto de soberanía con respecto a la derecha, Iglesias decía: "La soberanía no se defiende con bandera, se defiende con medidas de Gobierno". En lo relativo al libre comercio, Iglesias volvió a girar el debate hacia la necesidad de "pagar los impuestos en España", aprovechando para realizar una crítica contra las multinacionales que no lo hacen en el país.

\subsection{El minuto de oro}

El candidato de la fuerza de extrema derecha, Santiago Abascal, fue el encargado de presentar el minuto de oro. El discurso de Vox se basó en proposiciones de futuro (comenzando todas las frases con "queremos") a través de medidas para defender la unidad y la soberanía de España: ilegalización de partidos separatistas, reducir al máximo el gasto público, combatir la emigración y acabar con el Estado de las autonomías. En resumen, la dicotomía: igualdad frente a la dictadura progre.

El discurso de Ciudadanos se basó en la premisa: "Que no te digan que no se puede". Para ello, Rivera articuló un mensaje esperanzador: "Si se quieren cambiar las cosas, se puede". El público al que se dirigió su discurso fue la clase media trabajadora: "A los que se levantan cada día, contra viento y marea", o a los que montan "un proyecto frente a todos los obstáculos y la burocracia", haciendo referencia a su concepto recurrente en el debate: la verdadera revolución de la igualdad.

Pedro Sánchez empleó el minuto de oro para defenderse contra los ataques por los "pactos ocultos" planteando la dicotomía: verdad-mentira. Así, decía: "No hay nada más fuerte que la verdad". En la línea de marcar posición con respecto a Iglesias, Sánchez empleó el concepto Unidad de España para situarse en el centro. Unidad se relacionó con las políticas de la mayoría: "para salvaguardar la Unidad de España no hay que renunciar a la justicia social".

El discurso de Pablo Casado también partió de la estrategia de situarse en el centro, y se articuló en torno a dos ejes: "Frenar a los separatistas" y "resolver la crisis económica y social de la izquierda". A través del concepto España suma y todo lo que 
nos une, introdujo los tres actores de público afín e indeciso: pensionistas, jóvenes y familias que, según dice, necesitan que lidere "un Gobierno de verdad".

La apuesta de Iglesias partió de la estrategia de dar voz a una de las millones de ciudadanas españolas. La protagonista de su relato es una mujer joven, con estudios, que trabaja precaria en un empleo que no se corresponde con lo que ha estudiado, con diversidad funcional y que se quiere emancipar. Ella representa el miedo a la precariedad y a perder el empleo. Es una de tantas en España que representa lo que, en el debate, Iglesias apuntó que era el mayor problema de España: la temporalidad. Iglesias decía, tomándola como ejemplo: "Que nadie te convenza de que no se pueden cambiar las cosas", haciendo referencia a que sí es posible "un Gobierno que defienda a la gente".

\subsection{El análisis de Twitter}

Para el análisis de Twitter de @RTVE hemos partido de la tipología de encuadres de Ardèvol-Abreu (2015): conflicto, consecuencias, interés humano, moralidad y atribución de responsabilidad. Después, al analizar los tuits, hemos añadido a la definición lo que denominamos como tuits de contextualización del debate, dedicados a anunciar los minutos de oro, debates electorales o encuestas, entre otros; por otra parte, las presentaciones de los candidatos, que son tuits empleados para poner en alza una actuación del pasado de los partidos políticos, o para contextualizar las intenciones en el presente o en el futuro.

Con un total de 37 tuits dedicados al debate electoral organizado por RTVEy Antena3, hemos detectado que la mayor parte de ellos se dedican a la contextualización de los candidatos y el encuentro (17) así como a la interacción con los usuarios a través de encuestas o preguntas. Es decir, RTVE cumple una función sobre todo informativa. Le siguen los tuits de conflicto, un total de (9), de los cuales 5 son del líder popular Pablo Casado en los que habla sobre la corrupción, la crisis catalana (3) y las listas de espera. Por otro lado, tenemos solo 1 tuit de Rivera, centrado en corrupción y Cataluña, 1 de Iglesias preguntando a Casado por el 'solo sí es sí', es decir, relacionado con la violencia sexual; y 1 tuit en el que se apunta que Abascal e Iglesias discuten por la memoria histórica. 
20

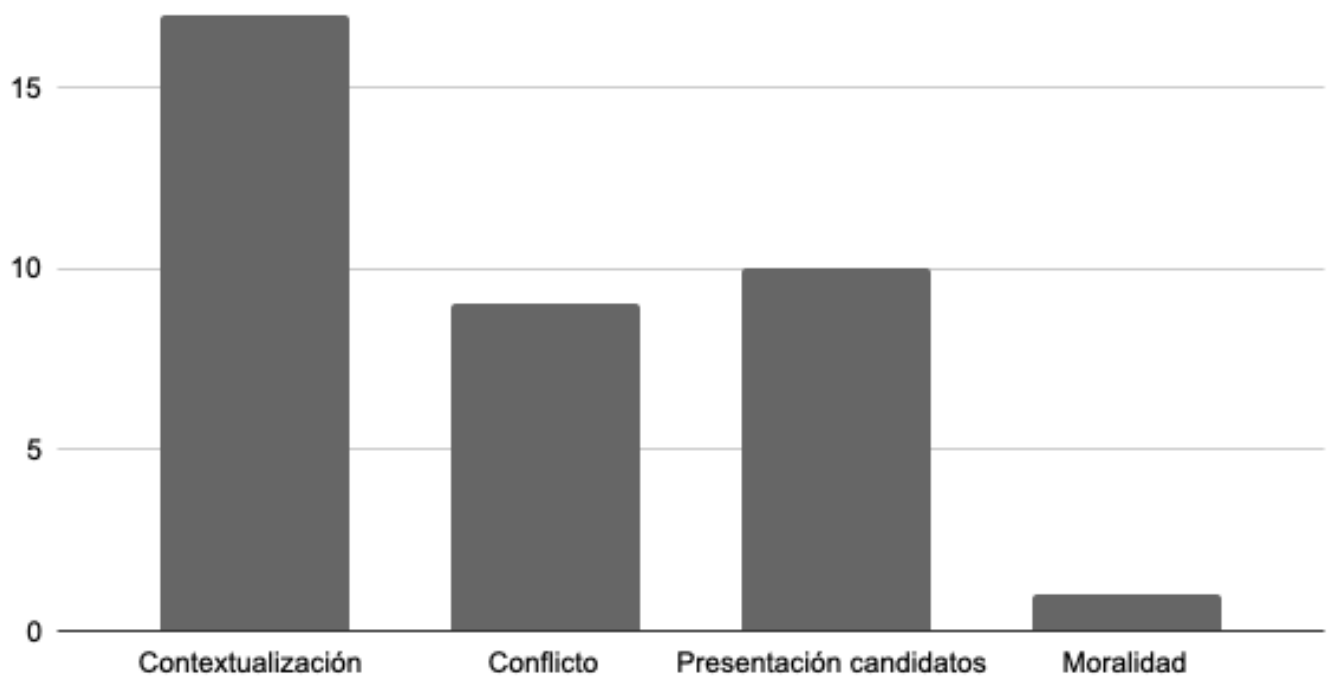

Gráfico 1. Encuadres de RTVE del debate electoral 10-N en Twitter

Fuente: Elaboración propia

En el tipo de encuadre de moralidad tenemos un tuit de la presentadora Ana Blanco. Resulta significativo porque la intervención de los moderadores se restringió a la moderación, salvo esta excepción. La periodista señalaba que no había mujeres políticas candidatas en el encuentro, apuntando que no representa una foto de igualdad. Esta intervención se reflejó en un tuit, que decía:

\section{@rtvenoticias·4 nov. 2019}

Ana Blanco, a los candidatos: "Me van a permitir que haga una referencia a la foto de este debate, con cinco candidatos y ninguna mujer presente. Supongo que hablarán de paridad, pero, en este momento, no es una foto de igualdad" \#Debatea5RTVE

Después, en la presentación de los candidatos, vemos 7 tuits de RTVE sobre Pedro Sánchez; 1 por parte de los demás candidatos políticos: Pablo Casado, Albert Rivera y Pablo Iglesias. En el caso de las medidas de Pedro Sánchez, como hemos indicado, RTVE publicó tuits atendiendo a la propia estrategia discursiva del líder del PSOE: medidas políticas para el futuro Gobierno y promesas de vicepresidencias. Estas fueron las dos estrategias propositivas del PSOE. Esto fue una constante en el debate, tanto por parte de Sánchez como de RTVE. Apuntamos dos ejemplos que lo muestran:

@rtve

Debate Electoral a 5 / Sánchez propone tres medidas en educación, sector audiovisual y código penal para Cataluña. \#Debatea5RTVE 
@rtve

VÍDEO / Sánchez anuncia que Calviño será la vicepresidenta Económica del Gobierno. \#Debatea5RTVE

\section{DISCUSIÓN Y CONCLUSIONES}

Las conclusiones del debate electoral del 10 de noviembre presentan dos vertientes. En primer lugar, debemos atender a la línea de ataque de los partidos políticos, que implica entender quién es el adversario según las encuestas o la predisposición de los partidos frente a futuros pactos de Gobierno. Pablo Casado articuló su discurso, en todos los bloques, contra el PSOE, en general, y Pedro Sánchez, en particular. El líder socialista atacó al Partido Popular por su gestión en los Gobiernos, con especial protagonismo en el de Mariano Rajoy, a la vez que criticó a Iglesias en su intención de acordar un Gobierno de coalición de izquierdas. Sánchez quería un gobierno en solitario. En la línea de estrategias de campañas electorales pasadas, Albert Rivera insistió en lo que, desde Ciudadanos, denominaron ICB (Impuesto de Corrupción al Bipartidismo) que supuso su foco de ataque. Mientras tanto, Santiago Abascal criticó la gestión de PSOE y PP (sobre todo en la cuestión catalana) y denominó a Podemos régimen totalitario.

Por otra parte, el debate tuvo cinco bloques, que fueron cohesión territorial, política económica, política social e igualdad, calidad democrática y política internacional. La declaración de independencia en Cataluña fue la protagonista del primer bloque, con dos interpretaciones: crisis por parte del PSOE y Unidas Podemos; ataque al Estado de derecho o desorden público (Partido Popular, Ciudadanos); y Golpe de Estado permanente, por parte de Santiago Abascal. En el bloque de política económica se interpretó la crisis en términos de enfriamiento de la economía (PSOE) y desaceleración económica (Unidas Podemos) por un lado. El Partido Popular acusó al PSOE de provocar la crisis mientras que el líder de Vox se refería a las autonomías para justificar el "despilfarro". Por su parte, Ciudadanos mencionó la pérdida de natalidad y la necesidad de ayudar a las "familias".

En el tercer bloque, reservado a las políticas sociales, Ciudadanos introdujo el concepto revolución de la igualdad para incorporar la idea de una "nación de ciudadanos libres e iguales" con su medida estrella: el contrato único. El Partido Popular elaboró, de nuevo, una crítica al PSOE por su gestión en el Gobierno, esta vez aludiendo al empleo, la sanidad y la educación. Iglesias centró el discurso en las políticas sociales y feministas, empleando la Constitución como herramienta para "proteger a la gente". Pedro Sánchez insistió, en este bloque, en las medidas sociales llevadas a cabo por el PSOE, así como en las propuestas de futuro. Se refirió a la derecha cobarde y la ultraderecha agresiva. Y Santiago Abascal planteó un discurso en base a la dicotomía: emergencias sociales frente a viejos odios del PSOE.

En el espacio de calidad democrática, Pablo Casado insistió en su crítica al PSOE, relacionando a Pedro Sánchez con los partidos nacionalistas. Pablo Iglesias continuó preguntando a Sánchez por los pactos, enfatizando su idea de la Constitución como programa político. En este bloque, Pedro Sánchez afirmó, intentando rebatir el concepto de viejos odios: "La España democrática es fruto del perdón pero no puede 
ser producto del olvido". Rivera, quitando peso a la cuestión de la memoria histórica, resumía su interpretación: "Superar el pasado y mirar al futuro". Santiago Abascal habló de que, dicha Ley, suponía enfrentar a quien se abrazó en la Constitución. Además, el candidato de Vox relacionó la calidad democrática con la llegada de Vox que, a su juicio, supuso el derecho a disentir.

El último bloque, de política internacional, lo introdujo el líder de Vox, Santiago Abascal, que insistió en que Bruselas produce crisis de convivencia. La solución consistiría en la soberanía de las naciones y la imposición de fronteras. Por su parte, Rivera articuló la estrategia de "Unidad de España en Europa", con presencia en Latinoamérica, así como la apuesta por la cultura del país y el comercio, a lo que denomina "la civilización". Pedro Sánchez habló de una Política migratoria humanitaria a la vez que defendió un Proyecto común europeo y halagó el cordón sanitario a la ultraderecha en Europa. Pablo Casado propuso la solución del Partido Popular: una Política europea en la que España sea esencial. Por último, Pablo Iglesias arrojó un cambio de marco en el concepto seguridad aportado por la derecha, insistiendo en que, frente la desaceleración y la guerra económica: la protección de los trabajadores.

Atendiendo a Pérez y García (2020) existe una táctica común de los candidatos políticos en el discurso en televisión y en Twitter, red que utilizan para la autopromoción de la campaña electoral (López, 2016; Suau, 2020). Sin embargo, hemos querido atender al actor en el que se crea ese discurso: la televisión. Según las conclusiones en América Latina de López y Oñate (2019), que apuntan que las televisiones públicas tienden a posicionarse con el líder oficialista, y las privadas con la oposición, el objetivo fue analizar si la televisión pública otorgó mayor cobertura a un candidato en detrimento de los demás. En el análisis de Twitter de @RTVE, con un total de 37 tuits, hemos percibido que 17 están dedicados a la contextualización del encuentro. Por lo tanto, RTVE cumple su función de servicio público siendo un actor que no se dedica a reproducir el contenido de los candidatos políticos: informa y propicia la conversación en redes sociales mediante encuestas y preguntas a los ciudadanos.

Después, encontramos un total de 9 tuits enmarcados en lo que hemos denominado como conflicto, entre los que se encuentran todos los candidatos: tuits dedicados a Rivera y Casado por la crisis Catalana; tuits sobre Pablo Casado mencionando la corrupción, la crisis de Cataluña y la gestión de lo público; Abascal e Iglesias discutiendo por la memoria histórica y Pablo Iglesias refiriéndose a la violencia sexual. Por su parte, en lo que denominamos como moralidad, únicamente encontramos un tuit sobre la periodista Ana Blanco realizado una crítica a la ausencia de mujeres candidatas a la presidencia del Gobierno. Por último, 10 tuits dedicados a la presentación de medidas de los candidatos de las cinco fuerzas políticas, entre los cuales extraemos un dato interesante: 7 tuits (70\%) estuvieron dedicados a hipotéticas medidas de Gobierno propuestas por el PSOE. Las propuestas de los candidatos en Twitter están mediadas por la televisión pública, que crea un relato propio sobre el debate televisivo. Confirmamos, como habían concluido López y Oñate (2019) que la televisión pública, en España, refleja su posicionamiento en el marco de presentación de candidatos, en el que otorgó más protagonismo a las medidas políticas del PSOE. Esta investigación refleja, en la línea de investigaciones previas, que la televisión 
pública, en España RTVE, proporcionó mayor cobertura a las medidas del líder oficialista, es decir, de Pedro Sánchez.

\section{REFERENCIAS}

Anstead, N. (2016). A different beast? Televised election debates in parliamentary democracies. The international journal of press/politics, 21(4), 508-526.

Ardèvol, A. (2015). Framing o teoría del encuadre en comunicación. Orígenes, desarrollo y panorama actual en España. Revista latina de comunicación social, (70), 423-450. https://doi.org/10.4185/RLCS-2015-1053

Aruguete, N. (2017). Agenda setting y framing: un debate teórico inconcluso. Más Poder Local, 36-42. https://ri.conicet.gov.ar/handle/11336/68048

Aruguete, N. (2013). La narración del espectáculo político: pensar la relación entre sistema de medios y poder político. Austral Comunicación, 2(2), 205-216. https://ri.conicet.gov.ar/handle/11336/3628

Barrientos, A., Caldevilla, D. y Vargas, J. (2019). El protocolo, la puesta en escena y la persuasión en los debates políticos televisados. Redmarka. Revista de Marketing Aplicado, 23(2), 17-27. https://doi.org/10.17979/redma.2019.23.3.5872

Bartolomé, M. y Rodríguez J. (2012). Pugna de frames en el debate político español sobre la situación económica (2008-2011). Estudios sobre el Mensaje Periodístico, 18, 439-457. http://dx.doi.org/10.5209/rev ESMP.2012.v18.n2.41018

Benoit, W. (2003). Topic of presidential campaign discourse and election outcome. Western Journal of Communication (includes Communication Reports), 67(1), 97112.

Boczkowski, P. J. \& Mitchelstein, E. (2015). La brecha de las noticias: La divergencia entre las preferencias informativas de los medios y el público. Ediciones Manantial.

Campo, M. (2017). La cara oculta de los debates electorales. Arpa.

Canel, M. (1998). Los efectos de las campañas electorales. Comunicación y sociedad. 11(1).

CIS. (2019). Macrobarómetro de octubre 2019. Preelectoral Elecciones Generales. http://www.cis.es/cis/export/sites/default/Archivos/Marginales/3260 3279/3263/Marginales/es3263mar Muestra global.pdf

Deltell, L. (2014). Audiencia social versus audiencia creativa: caso de estudio Twitter. Estudios sobre el mensaje periodístico, 20(1), 33-47. https://doi.org/10.5209/rev ESMP.2014.v20.n1.45217

Donsbach, W. (1995). Contenidos, utilización y efectos de la comunicación política. Comunicación Política, 41-67. 
Edelman, M. \& Piatigorsky, J. (1991). La construcción del espectáculo político. Manantial.

Entman, R. (1993). Framing: Toward clarification of a fractured paradigm. Journal of communication, 43(4), 51-58.

Entman, R. (2003). Cascading activation: Contesting the White House's frame after 9/11. Political Communication, 20(4), 415-432.

Hallin, D. \& Mancini, P. (2004). Comparing media systems: Three models of media and politics. Cambridge University Press.

Haselmayer, M., Wagner, M. y Meyer, T (2017). Partisan bias in message selection: media gatekeeping of party press releases. Political communication, 34(3), 367384. https://doi.org/10.1080/10584609.2016.1265619

Jivkova, D., Padilla, G. y Pernía, N. (2016) El debate sobre el estado de la nación como parte del ritual democrático-parlamentario: análisis del discurso de Rajoy y Rubalcaba en 2014. Estudios sobre el mensaje periodístico, 22.1, 375-390. https://core.ac.uk/reader/45655300

Kalsnes, B. \& Larsson, A. (2019). Facebook News Use During the 2017 Norwegian Elections-Assessing the Influence of Hyperpartisan News. Journalism Practice (2019), 1-17. https://doi.org/10.1080/17512786.2019.1704426

Lilleker, D., Koc, K., Negrine, R., Gibson, R., Vedel, T. y Strudel, S. (2017). Social media campaigning in Europe: Mapping the terrain. Journal of Information Technology \& Politics. https://doi.org/10.1080/19331681.2017.1397239

López, A. (2016). Twitter-retórica para captar votos en campaña electoral. El caso de las elecciones de Cataluña de 2015. Comunicación y hombre, (12), 97-118.

López-López, P. C., Oñate, P. (2019). De la videopolítica a la ciberpolítica: debate entre candidatos y televisiones en cinco elecciones presidenciales. El profesional de la información, 28(5), e280512. https://doi.org/10.3145/epi.2019.sep.12.

López, P., Rivera, I., \& Araújo, J. (2017). La comunicación política en las elecciones gallegas del 25 de septiembre de 2016: la agenda temática en el debate de la TVG. Sociedad Latina de Comunicación Social. http://www.revistalatinacs.org/16SLCS/2016 libro/070 Lopez.pdf

Luengo, Ó. (2011). Debates electorales en televisión: una aproximación preliminar a sus efectos inmediatos. Revista Española de Ciencia Política, 25, 81-96.

Marcos, S., Alonso, L. \& López, A. (2021). Campañas electorales y Twitter. La difusión de contenidos mediáticos en el entorno digital. Cuadernos. info, 48, 27-47. https://doi.org/10.7764/cdi.48.27679 
McCombs, M. \& Shaw, D. (1972). The agenda-setting function of mass media. Public opinion quarterly, 36(2), 176-187.

McCombs, M. (2006). Estableciendo la agenda/setting the agenda: el impacto de los medios en la opinión pública y en el conocimiento. España. Madrid: Grupo Planeta (GBS).

Ohme, J., Marquart, F. y Kristensen, L. (2019). School lessons, social media and political events in a get-out-the-vote campaign: successful drivers of political engagement among youth? Journal of Youth Studies, 1-23.

Padilla, G. (2015). La espectacularización del debate electoral: estudio del caso en Estados Unidos. Vivat Academia, 107-123.

Pérez, C. y García, M. (2020). Del debate electoral en TV al ciberdebate en Twitter. Encuadres de influencia en las elecciones generales en España (28A). El Profesional de la información, 29(4), e290405. https://doi.org/10.3145/epi.2020.jul.05

Richardson, J., Huddy, W. y Morgan, S. (2008). The Hostile Media Effect, Biased Assimilation, and Perceptions of a Presidential Debate. Journal of Applied Social Psychology, 38 (5), 1255-1270.

Rodríguez, A. y Rodríguez, R. (2010). La circulación social de los encuadres periodísticos en tiempo de campaña electoral: Transmisión, influencia y atribución $\begin{array}{llr}\text { de } \quad \text { responsabilidad. } & \text { 15(29), } & \text { 193-212. }\end{array}$ https://addi.ehu.es/bitstream/handle/10810/41034/1652-5316-1PB.pdf?sequence $=1$ \&isAllowed $=y$

RTVE (2019). Debate a cinco en RTVE / Elecciones 10N. [Programa televisivo]. Disponible en web https://www.youtube.com/watch?v=7SKDcB1100o\&t=7217s España, Madrid.

Rúas, J. y Quintas, N. (2020). Televisión, audiencias y debates electorales: hacia la multipantalla. El profesional de la información (EPI), 29(2), e290201. https://doi.org/10.3145/epi.2020.mar.01

Schrott, P. (1990). Electoral consequences of "winning" televised campaign debates. Public Opinion Quarterly, 54(4), 567-585.

Simón, P. (2017). The challenges of the new Spanish multipartism: government formation failure and the 2016 general election. South European Society and Politics, 21(4), 493-517. https://doi.org/10.1080/13608746.2016.1268292

Suau, G. (2020). Microblogging electoral: la estrategia comunicativa de Podemos y Ciudadanos en Twitter en las campañas electorales del 20D y el 26J. Prisma social, 28, 103-26. 
Trigueros, J. y Lacasa, I. (2018). Colloquy with Maxwell McCombs at the University of Texas at Austin: agenda setting, a limitless theory in a connected world. Church, Communication and Culture, 3(1), 53-74. 10.1080/23753234.2018.1430513

Van der Meer, T., Walter, A. y Aelst, P. (2016). The contingency of voter learning: How election debates influenced voters' ability and accuracy to position parties in the 2010 Dutch election campaign. Political Communication 33.1, 136-157. $\underline{10.1080 / 10584609.2015 .1016639}$

\section{AUTORES}

\section{Tania Brandariz Portela}

Máster en Comunicación Política. Doctoranda en Periodismo en la Universidad Complutense de Madrid. Las líneas de investigación sobre las que trabaja comprenden la Teoría Feminista, la Comunicación Política y los efectos de los medios de comunicación.

Orcid ID: https://orcid.org/0000-0002-0578-3986 